\title{
Effectiveness of $0.2 \%$ Glyceryl Trinitrate and $0.5 \%$ Nifedipine in the Treatment of Chronic Anal Fissure
}

\author{
Suman Kumar Shrestha, 'Prabin Bikram Thapa, 'Dhiresh Kumar Maharjan,, Tseten Yonjan Tamang' \\ 'Department of Surgery, Kathmandu Medical College Teaching Hospital, Sinamangal, Kathmandu, Nepal.
}

\begin{abstract}
Introduction: Anal fissure is an ischemic ulcer caused by combination of spasm of internal anal sphincter and poor blood supply to the posterior midline of anal canal. This study aimed to assess the efficacy of Glyceryl Trinitrate and Nifedipine in the treatment of chronic anal fissure.

Methods: Ninety patients with symptomatic anal fissure in Kathmandu Medical College Teaching Hospital are allocated for study in two groups of 45 each from March 2013 to April 2014. The patients are assigned alternatively to GTN group and Nifedipine group. All patients were assessed every week till 8 weeks in regards to headache, compliance, healing and recurrence. The patients who had complete healing in 8 weeks were further followed up for 6 weeks to detect recurrence.
\end{abstract}

Results: Patients in the two groups were comparable in regard to demographic data (age and sex) as well as clinical factors. Headache was main complaint of patients using GTN in high percentage (16.6\%) than complained by patients using topical Nifedipine (6.9\%). This factor led to poor compliance with GTN compared with Nifedipine. Nifedipine showed better healing rate $82.5 \%$ compared with GTN 60\%. Recurrence was comparable among the two groups.

Conclusions: Nifedipine ointment showed better results than GTN ointment in chronic anal fissure regarding headache, compliance, healing and recurrence in 6 weeks of follow up period after complete healing of fissure in 8 weeks.

Keywords: anal fissure; glyceryl trinitrate; nifedipine.

\section{INTRODUCTION}

Anal stretching was the treatment for chronic anal fissure in the past and now has been replaced by lateral sphincterotomy as the former resulted in more anal incontinence up to $35 \%$ of the patients lifelong. ${ }^{1}$ Commonly used chemicals are Glyceryl trinitrate (GTN) and Diltiazem ointments which induce initial sphincter relaxation resulting in healing of ulcer. However, there is still higher recurrence rate and troublesome severe headache. ${ }^{2,3}$ The pain caused by the fissure has been relieved by the application of local anesthetic agents but spasm in the anal canal doesn't not fall resulting in non-healing of fissure. ${ }^{4}$ Anal fissure is a common ischemic ulcer associated with high anal tone. Nonpermanent chemical denervation with botulism toxin to induce temporary sphincter paresis has demonstrated

Correspondence: Dr. Suman Kumar Shrestha, Department of Surgery, Kathmandu Medical College Teaching Hospital, Sinamangal, Kathmandu, Nepal. Email: suman_shrestha@hotmail.com, Phone: +977. 9851032851 . 
encouraging results. ${ }^{5}$

With so many potentially conservative approaches, we investigated the roles of various nonsurgical methods using GTN and Nifedipine in the treatment of chronic anal fissure.

\section{METHODS}

This was a prospective observational study carried out in Kathmandu Medical College Teaching Hospital from March 2013 to April 2014. Approval for the research from the ethical committee of KMCTH was taken. All the patients were subjected to thorough history and physical examination. Informed consent was taken from all patients

The study included patients with chronic anal fissure with duration more than 8 weeks and who failed to recover after conservative management including sitz bath, stool softener and high fiber diet. Patients, who on examination had posterior fissure with indurations at edge, anal tag and visible horizontal fibers of internal anal sphincter were included in the study.

Patients with history of reaction to topical agents and associated disease at perianal region, such as fistula, hemorrhoids and abscess were excluded from the study. Perianal ulcers related with tuberculosis, HIV, Chrohn's disease, leukemia were also excluded from the study. Patients who were not willing to come for follow up were excluded. Pregnant patients and patients with cardiovascular diseases were also excluded from the study.

Ninety patients were enrolled in the study. Patients were randomly allocated to two groups. Group A patients of 45 were subjected to $2 \%$ GTN two times daily for eight weeks and group B of 45 patients were subjected to $0.5 \%$ Nifedipine ointment two times daily for eight weeks. Patients were instructed to apply ointments with gloves in and around anus for one centimeter deep and circumferentially. Patients were also prescribed with 15 $\mathrm{ml}$ of lactulose solution to take daily at bed time.

Patients were followed up every two weeks for two months for checking healing of ulcer and every two months for six months for checking recurrence after healing. During follow ups adverse effects of medication was also noted and rerecorded. These patients were also offered an alternative treatment. Patients who did not show complete healing in 8 weeks were offered surgical treatment in the form of lateral sphincterotomy. Patient's compliance to the treatment is also noted during the follow up visits. Noncompliant patients were subjected to surgery.

Frequency, percentage, mean and standard deviation were applied. Unpaired student $t$ test and $X 2$ test were used as a test of significance.

\section{RESULTS}

Patients in both groups were compared with respect to age and sex as well as clinical pictures associated with the anal fissures (pain, bleeding, pruritus, tenderness and duration of symptoms) (Table 1). Some patients did not come for the follow ups and were excluded from the study. A total of 90 patients were included in the study and were given either GTN or Nifedipine (Figure 1). Treatment side effects (headache, flushing) with GTN were seen in 7 out of 42 patients (16.6\%). 3 out of $43(6.9 \%)$ patients using Nifedipine had side effects which was significantly higher $(\mathrm{P}<0.01)$ in comparison to GTN. Headache was the cause of intolerability for continuing the treatment. Healing after 8 weeks was higher with Nifedipine, seen in 33 out of 40 patients ( $82.5 \%$ ) as compared to GTN (21 out of 35 patients $(60 \%)$ showed healing after 8 weeks) and this difference is statistically insignificant $(P<0.04)$. Patients from both groups: GTN (5 out of 21 i.e $23.8 \%$ ) and Nifedipine (6 out of 33 i.e $18.1 \%$ ) showed comparable results as regards to recurrence after 6 months (Table 2).

\begin{tabular}{|lccc|}
\hline \multicolumn{3}{|l|}{ Table 1. Demography of patients in two groups. } \\
\hline Particulars & GTN Group & $\begin{array}{l}\text { Nifedipine } \\
\text { Group }\end{array}$ & P-value \\
$\begin{array}{l}\text { Age } \\
\text { (Mean } \pm \text { SD) }\end{array}$ & $36.2 \pm 11.6$ & $35.7 \pm 13.6$ & 0.56 \\
$\begin{array}{l}\text { Sex(Male/ } \\
\text { Female) } \\
\text { Duration of } \\
\text { symptoms } \\
\text { in weeks } \\
\text { (Mean } \pm \text { SD) }\end{array}$ & $19 / 26$ & $20 / 25$ & 0.54 \\
\hline
\end{tabular}

Significance $(P<0.05$ 


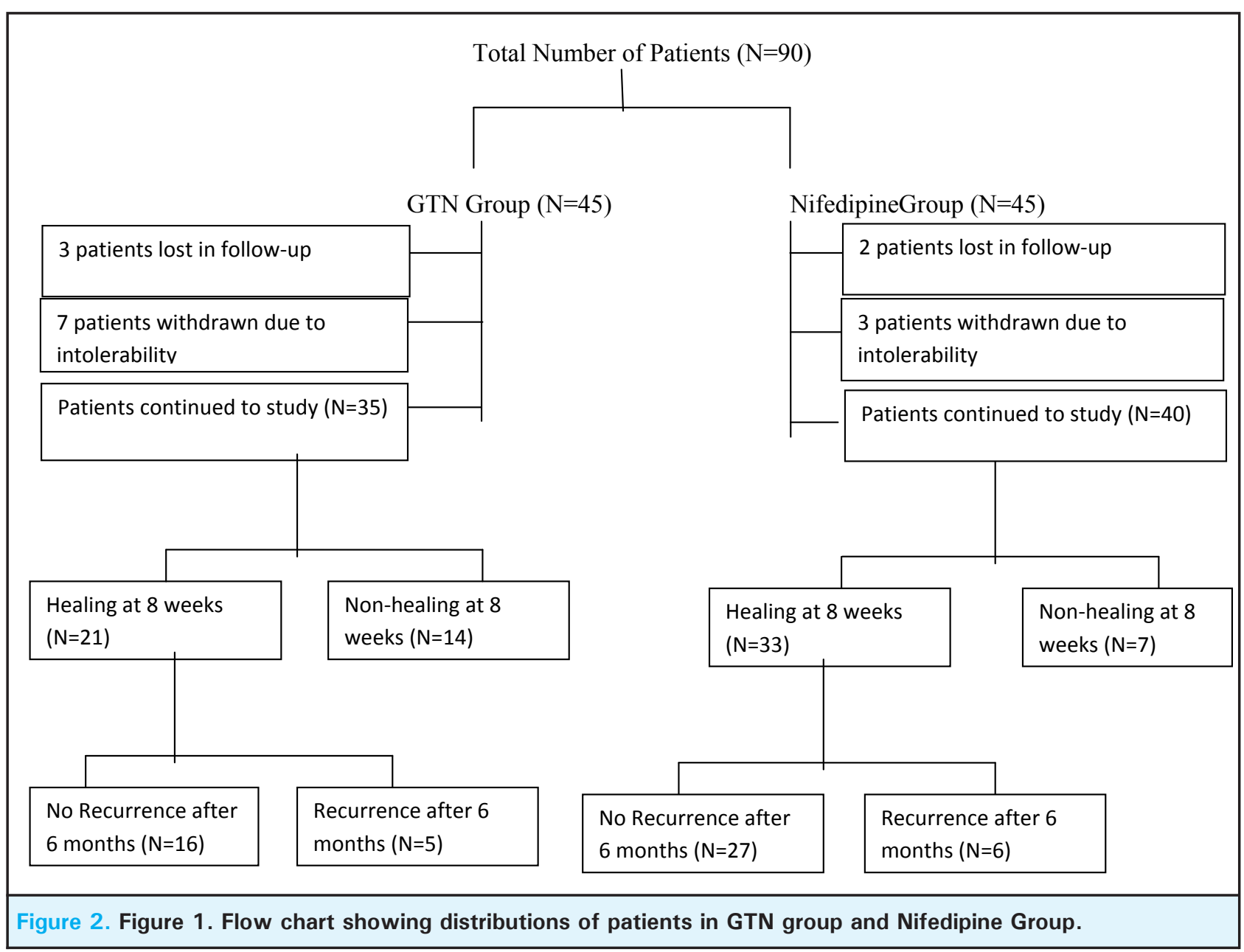

\begin{tabular}{|c|c|c|c|}
\hline & GTN Group & $\begin{array}{l}\text { Nifedipine } \\
\text { Group }\end{array}$ & P-value \\
\hline Headache & $7 / 42(16.6 \%)$ & $3 / 43(6.9 \%)$ & $<0.01$ \\
\hline $\begin{array}{l}\text { Healing (8 } \\
\text { weeks) }\end{array}$ & $21 / 35(60 \%)$ & $33 / 40(82.5 \%)$ & $<0.03$ \\
\hline $\begin{array}{l}\text { Recurrent (6 } \\
\text { month) }\end{array}$ & $5 / 21(23.8 \%)$ & $6 / 33(18.1 \%)$ & $<0.01$ \\
\hline
\end{tabular}

\section{DISCUSSION}

Chronic anal fissures are associated with spasm and hyper tonicity of the anal sphincters. The spasm leads to ischemia of anal canal which complicate fissure healing. Internal lateral sphincterotomy is effective but can cause flatus and feces incontinence sometimes permanently. ${ }^{6} \quad$ Topical application of Nifedipine can effectively produce chemical sphincterotomy temporarily with healing of fissure while avoiding those complications of surgical procedures. ${ }^{7}$ But side effects of these agents are headache in about $40 \%$ of the cases and again the recurrence rate is also high
(19\%).8-10 Apart from lateral sphincterotomy posterior midline sphincterotomy, dermal flap coverage of the fissure has also been tried but morbidity being the same incontinence. Chemical sphincterotomy is reversible, repeatable with low risk and can be used in patients unwilling for surgery. ${ }^{11}$

Reduction of sphincter spasm can be achieved by injecting Botulinum toxin onto the anal sphincter. The main side effect of this procedure is temporary fecal incontinence in about $2 \%$ of the cases. ${ }^{12}$

GTN, calcium channel blockers, Botulinum toxin and hydrocortisone are all effective therapies for anal fissure and superior to Lidoaine which is nearly equivalent to placebo. ${ }^{13,14}$

Faster complete healing of fissures with Minoxidil and Lignocaine combination was related to synergistic action of the two drugs that is Minoxidil relieving anal spasm and Lignocaine inducing pain relief. ${ }^{15}$ Nitroglycerine ointment is a nitric oxide donor which improves anodermal perfusion thus reducing anal resting pressures. Lund and Scholefield showed healing in $68 \%$ in 8 weeks by using GTN but more recent study 
reported lower healing rate of $30 \%$ at 6 weeks. The main side effect of GTN was headache which limited its use. ${ }^{3,15}$

Nifedipine ointment, a calcium channel blocker reduces sphincter tone and promotes fissure healing. Parrott's and colleagues reported the tissue healing was $94 \%$. No systemic side effects were noted. Recently Nifedipine was found to be superior to GTN with respect to both healing and side effects. ${ }^{3,16}$

In this study, headache was the most important side effect contributing to intolerability and non compliance to the treatment. Patients treated with GTN showed a higher incidence of headache in comparison to patients using Nifedipine. Headache was the cause of the withdrawal from the study which was higher in the group using GTN than the group using Nifedipine.

The healing rate in 8 weeks was higher for Nifedipine $(82.5 \%)$ in comparison to topical GTN (60\%). This is comparable to the other studies. Patients who received Nifedipine ointment showed significant improvement in healing after 6 months of the treatment compared with GTN. The healing after GTN application showed great variability this treatment verifies its usefulness and efficacy in Sudanese patients. ${ }^{17}$ Studies showed 30$68 \%$ healing rate with using $\mathrm{GTN}^{3,15}$ while some studies indicated $94 \%$ of healing rate with using Nifedipine ${ }^{3,16}$ which is quite higher than that of our studies. Dissimilar clinical results may be because of variation in preparation of the ointments.

Likewise reoccurrence rate in 6 months is slightly more in GTN group(23.8\%) than in Nifedipine group(18.1\%). Recurrence after complete healing was recorded up to 6 months after cure. Recurrence rate in both groups are comparable and similar to other studies. . $^{3,15,16,17}$

\section{CONCLUSIONS}

Application of topical Nifedipine in the treatment of chronic anal fissure showed better results compared with GTN in relation to compliance to the treatment, occurrence of headache, healing rate and recurrence.

\section{Conflict of Interest: None.}

\section{REFERENCES}

1. Tiberiu E, Sergio S. Topical Nifedipine vs. Topical Glyceryl Trinitrate for the Treatment of Chronic anal Fissure. Disease Colon Rectum. 2003;805-7. [PubMed]

2. Mohammed A, Walid A, Khalid S. Mohamed M. Treatment of Chronic Anal Fissure in Adults Using 0.2\% Glyceryl trinitrate versus $0.5 \%$ Nifedipine Ointments : A Prospective Randomized Controlled Trial in Two Centers. Med. J. Cairo Univ. 2012; 833-38. [Full Text]

3. Philippe T, Daniel CT, Charles V, Joel BF. Nonsurgical Treatment of Chronic Anal Fissure: Nitroglycerin and Dilatation versus Nifedipine and Botulinum Toxin. Can. J. surg. 2006;49:41-5. [pubMed]

4. Aytac B, Cakar s. Anal Canal Pressure in Anal Fissure before and After Internal Sphincterotomy. Acta chir belg. 2003;103:511-2. [PubMed]

5. Dziki A, Trzcinski R, Langner E, Wronski W. New Approaches to the Treatment of Anal Fissure. ACI 2004;XLIX:73-5. [PubMed]

6. Leah SS, Rick G. Are Non-surgical Treatments for Anal Fissure Effective? Canadian Family Physician. 2000;46:1063-5. [PubMed]

7. Kemseke CV, Belaiche j. Medical Treatment of Chronic Anal Fissure. Where do we stand on Reversible Chemical Sphincterotomy. Acta gastro- Enterologica Belgica. 2004; LXVII:265-71. [PubMed]

8. Farzaneh G, Parisa G, Alireza K, Sayed SSM. The Effect of Topical Nifedipine in the Treatment of Chronic Anal Fissure. Acta medica iranica. 2009;48:295-9. [PubMed]
9. Antinio C, Pasquale M, Giuditta M, Alberto DA. Oligo-Antigenic Diet in the Treatment of chronic Anal Fissures. Evidence for a Relationship Between Food and Hypersensitivity an d Anal Fissures. Am J Gastroenterol. 2013;108:835-832. [PubMed]

10. Trent G, Lynne B, Chrispen M, Mohamed A. Glyceryl Trinitrate Ointment Did Not Reduce Pain After Stapled Hemorrhoidectomy: A Randomized Controlled Trial. Int Surg. 2012;92:112-9. [PubMed]

11. Richard N. A Systematic Review of Medical Therapy for Anal Fissure. Dis Colon Rectum. 2004;47:4422-30. [PubMed]

12. McCallion K, Gardiner KR. Progress in the Understanding and Treatment of Chronic Anal Fissure. Postgrad med j. 2001;77:753-79. [PubMed]

13. Fazila H, Muhammad MM, Abdul MK. Efficacy and Side Effects of Glyceryl Trinitrate in Management of Chronic Anal Fissure. J Ayub Med Coll Abbottabad. 2012;24:227-31. [PubMed]

14. Charles O, Jan R, Brian WP, Hyman N, Donald B. Practice Parameters for the Management of Anal Fissures. Dis Colon Rectum. 2004;47:2003-7. [PubMed]

15. Muthukmarassamy R, Robinson SS, Sarath CS, Raveendran R. Indian Journal of Gastroenterology. 2005;24:158-60. [PubMed]

16. Peroth P, Bove A, Antropoli C, Molino D. Topical Nifedipine for Anal Fissures. Disease Colon Rectum. 2002;45:1468-75. [PubMed]

17. Hisham MA. Comparative Study of Oral and Topical Nifedipine in the Treatment of Chronic Anal Fissure. Sudanese Journal of Public Health. 2010;5:203-6. [PubMed] 